François Provenzano, Vies et mort de la francophonie. Une politique française de la langue et de la littérature

\title{
Hugues Sheeren
}

\section{(2) OpenEdition}

\section{Journals}

Édition électronique

URL : http://journals.openedition.org/studifrancesi/3880

DOI : 10.4000/studifrancesi.3880

ISSN : 2427-5856

Éditeur

Rosenberg \& Sellier

\section{Édition imprimée}

Date de publication : 1 décembre 2012

Pagination : 615-616

ISSN : 0039-2944

\section{Référence électronique}

Hugues Sheeren, «François Provenzano, Vies et mort de la francophonie. Une politique française de la langue et de la littérature », Studi Francesi [En ligne], 168 (LVI | III) | 2012, mis en ligne le 30 novembre 2015, consulté le 07 mars 2021. URL : http://journals.openedition.org/studifrancesi/3880 ; DOI : https://doi.org/10.4000/studifrancesi.3880

Ce document a été généré automatiquement le 7 mars 2021.

\section{(c) $($ ) $\odot$ (8)}

Studi Francesi è distribuita con Licenza Creative Commons Attribuzione - Non commerciale - Non opere derivate 4.0 Internazionale. 


\title{
François Provenzano, Vies et mort de la francophonie. Une politique française de la langue et de la littérature
}

\author{
Hugues Sheeren
}

\section{RÉFÉRENCE}

FRANÇOIS PROVENZANO, Vies et mort de la francophonie. Une politique française de la langue et de la littérature, Bruxelles, Les impressions nouvelles, «Réflexions faites», 2011, pp. 288.

1 Prolongement d'une thèse de doctorat, l'ouvrage émane d'un jeune chercheur à l'Université de Liège, ancien étudiant de Jean-Marie Klinkenberg aujourd'hui spécialisé dans le domaine de la rhétorique des discours théoriques, de la sémiologie et de l'histoire sociale des discours. Divisé en six chapitres, ce volume s'ouvre sur un avantpropos susceptible d'ébranler d'emblée certaines convictions ancrées chez le lecteur, qui se voit affirmer que «la francophonie n'a pas d'histoire». En effet, l'historiographie désigne presque toujours Onésime Reclus, inventeur du mot, comme celui qui est également à l'origine du concept. Or François Provenzano tient à prendre ses distances par rapport à la périodisation outrancière qui détaille les «différentes étapes de la construction francophone» en démontrant que cette tentative d'historicité n'a guère de sens car il existe déjà une "proto-francodoxie» avant Reclus, c'est-à-dire un ensemble de traditions, de discours qui témoignent de l'existence d'une représentation des écrits littéraires produits hors des frontières françaises.

2 À cet égard, le titre-choisi, comme il arrive souvent, par l'éditeur-est assez emblématique. Le premier substantif est au pluriel alors que le second, se référant on ne peut plus clairement à l'extinction d'un concept, est au singulier; la francophonie a «connu plusieurs vies, mais tend aujourd'hui à s'éteindre définitivement» dit l'auteur, entendons par là qu'elle s'est manifestée à différents moments de l'histoire sous des formes diverses et que le flou qui entoure cette notion est lié au fait qu'on touche à 
différents domaines, allant du littéraire au politique, du linguistique au culturel. De fait, l'ouvrage lui-même comprend différents volets: une partie historique où l'auteur s'attarde sur l'évolution du mot et du concept de francophonie en s'appuyant sur des discours ou des textes émanant de différentes personnalités et au cours de laquelle il démonte l'idée que cette notion est née d'un surgissement spontané bien identifiable dans le temps (au contraire, la construction francophone s'est faite de manière assez aléatoire); ensuite un volet critique teinté d'un regard socio-littéraire mettant en exergue le poids de la France qui continue à peser, quoi qu'on en dise, et rend totalement dépendants d'elle les écrivains francophones dont le regard est toujours tourné vers l'Hexagone; enfin, un volet politique qui passe en revue et analyse de façon minutieuse les harangues prononcées par des célébrités politiques, ministres ou anciens coloniaux (Xavier Deniau, Jacques le Cornec), des hommes de lettres (Philippe de Saint-Robert, Jean-Louis Roy) ou encore des personnalités ayant occupé ou occupant un poste important au sein des grandes instances francophones comme Jean-Marc Léger. Certes, l'auteur a dû établir des choix. On pourrait lui reprocher de n'avoir pas inséré telle ou telle figure, de s'être trop focalisé sur un auteur, ou encore d'avoir privilégié une période plutôt qu'une autre, mais Provenzano anticipe les critiques qu'on pourrait lui adresser, conscient de ce que le sujet est vaste et qu'il faut forcément exclure certaines personnalités, au risque de se le voir reprocher.

3 L'ouvrage est fouillé, clair et exemplifié. C'est le travail pointu d'un spécialiste qui touche à une matière complexe, un travail qui exige qu'on se familiarise d'abord avec certaines notions (comme celle de «francodoxie», qui constitue un chapitre entier), mais qui en même temps n'est pas réservé à la seule intelligentsia; bien que poussé, le livre reste accessible tant au niveau du contenu que du style.

Le lecteur, au fil des pages, ne cesse de voir se confirmer une idée: malgré le message que la France tente de véhiculer, celui d'un pays ouvert à la diversité culturelle, au métissage, à la variété, c'est-à-dire l'idée d'une nation prête à accepter d'être mise sur le même pied que les «cousins francophones» dans un esprit fraternel en faisant fi de tout sentiment de supériorité, on se rend compte que l'Hexagone est lui-même pris dans ses propres contradictions et que son unique préoccupation est d'utiliser la francophonie pour mieux régner d'un point de vue politique, soit d'être encore davantage présent sur la scène internationale. Ainsi, cette forme d'humanisme politiquement correcte présentée comme une tentative de "communion culturelle désintéressée» ne servirait en fait qu'à assurer à la France son propre rayonnement. À cet égard, l'auteur est assez réaliste et ne manque pas de mettre le doigt sur le fait que les instances de consécration des écrivains sont une affaire purement hexagonale (à l'instar des critères esthétiques servant à sélectionner les «bons» écrivains): les francophones récompensés à Paris ne sont pas forcément reconnus en tant que tels et, de ce fait, ces «petits cousins francophones» dont le talent égale les lettrés de la France métropolitaine contribuent d'une certaine façon à garantir la pérennité de l'hégémonie française.

5 À l'heure de la mondialisation, où des écrivains francophones revendiquent une «littérature-monde», à une époque où émerge à nouveau une forme de rattachement à sa propre identité nationale, où le sarkozysme semble vouloir renouer avec certains discours coloniaux impérialistes et où le français ne cesse de reculer face à l'anglais, il y a lieu de s'interroger, en effet, sur une notion qui est probablement en voie d'extinction. 